\title{
Remineralization of Eroded Enamel Lesions by Simulated Saliva In Vitro
}

\author{
Robert L. Karlinsey $^{\mathrm{a},{ }^{*}}$, Allen C. Mackey ${ }^{\mathrm{a}}$, Douglas D. Blanken ${ }^{\mathrm{a}}$ and Craig S. Schwandt ${ }^{\mathrm{b}}$ \\ ${ }^{a}$ RL Karlinsey, Indiana Nanotech, 351 West $10^{\text {th }}$ Street, Suite 309, Indianapolis, Indiana, 46202 USA \\ ${ }^{b}$ McCrone Associates, Inc., 850 Pasquinelli Drive, Westmont, IL 60559-5539 USA
}

\begin{abstract}
Purpose: The purpose of this study was to evaluate the effects of two simulated saliva (SS) remineralization solutions comprising different calcium-inorganic phosphate $\left(\mathrm{Ca} / \mathrm{P}_{\mathrm{i}}\right)$ ratios on eroded enamel.

Methods: $3 \mathrm{~mm}$ diameter enamel cores were extracted from bovine teeth, mounted in acrylic rods, ground and polished, and initially demineralized with either $0.3 \%$ (120 minutes) or $1.0 \%$ (30 minutes) citric acid solutions ( $\mathrm{pH} 3.8)$. Both sets of initially eroded specimens were evaluated for surface microhardness $(\mathrm{N}=10)$ and treated with either 0.3 or $1.6 \mathrm{Ca} / \mathrm{P}_{\mathrm{i}}$ ratio SS. Groups were first exposed to a seven-day remineralization period and then were cycled in a three-day regimen consisting daily of three rounds of two-hour plus overnight SS treatments and three 10-minute static immersions in demineralization solution. Specimens were assessed using surface microhardness and scanning electron microscopy.

Results: Initial erosion from $0.3 \%$ citric acid led to elliptical-shaped pore openings several microns in length and in depth and contrasted significantly with respect to $1 \%$ citric acid. The greatest remineralization was observed from the $0.3 \mathrm{Ca} / \mathrm{P}_{\mathrm{i}}$ $\mathrm{SS}$, while the $1.6 \mathrm{Ca} / \mathrm{P}_{\mathrm{i}} \mathrm{SS}$ produced the least.

Conclusions: This study demonstrated the nature of remineralization of eroded enamel depends on both initial erosive conditions and the $\mathrm{Ca} / \mathrm{P}_{\mathrm{i}}$ ratio of simulated saliva.
\end{abstract}

Keywords: Citric acid, calcium, phosphate, scanning electron microscopy, microhardness.

\section{INTRODUCTION}

Though readily observable but relatively difficult to measure, model and treat, dental erosion is a complicated challenge for investigators $[1,2]$. While clinical evaluations are ultimately and critically needed to investigate dental erosion for a given population, in vitro modeling can contribute important data that may help shape clinical expectations $[1$, $3,4]$. For example, evaluation of a promising treatment that may provide anti-erosion benefits could be explored in an in vitro model to help identify proper dosing [5] that, in turn, establishes grounds for follow-on clinical evaluation [6]. While in vitro models are not expected to perfectly emulate the clinical setting, their contribution to basic understanding and for initial screening of anti-erosion treatments render them important tools in the study of dental erosion $[3,4]$.

Dental erosion can be influenced by the presence and concentration of agents such as calcium, phosphate and fluoride, whether they are found in the acidic beverage or foodstuff, anti-erosion treatment or remineralization solution (i.e. actual or simulated saliva) [6-16]. The extent of dental erosion also depends on the presence and nature of the acquired pellicle, which has a protective role [17-19]. Typical investi-

*Address correspondence to this author at the Indiana Nanotech, 351 West $10^{\text {th }}$ Street, Suite 309, Indianapolis, Indiana, 46202 USA;

Tel: +1-317-278-7892; Fax: +1317-278-4102;

E-mail: rlk.nanotech@gmail.com gations emphasize the presence of the pellicle, calcium, phosphate and fluoride whereas few investigations have explored the ratio of calcium-inorganic phosphate $\left(\mathrm{Ca} / \mathrm{P}_{\mathrm{i}}\right)[15$, 16]. Previously, we evaluated the ability of remineralization solutions with different $\mathrm{Ca} / \mathrm{P}_{\mathrm{i}}$ ratios, including 1.6 , which might favor hydroxyapatite formation [20] and 0.3 , which is found naturally in saliva [21], to remineralize eroded dentin substrates [15]. However, the evaluation of different $\mathrm{Ca} / \mathrm{P}_{\mathrm{i}}$ ratios has not been considered for eroded enamel, let alone for erosion prepared under different initial conditions. Since saliva can provide natural protective benefits against erosion, exploring the $\mathrm{Ca} / \mathrm{P}_{\mathrm{i}}$ ratio of simulated saliva remineralization solutions on eroded enamel might bear on future in vitro modeling as well as correlations with in situ and/or in vivo observations.

The purpose of this exploratory study was to evaluate the effects of two simulated saliva remineralization solutions comprising different $\mathrm{Ca} / \mathrm{P}_{\mathrm{i}}$ ratios on eroded enamel. This study involved eroded enamel lesions initially formed under two different conditions and evaluated in an in vitro model consisting of a remineralization phase followed by a shortterm $\mathrm{pH}$ cycling phase. The null hypothesis is that there would be no differences between the two simulated saliva remineralization solutions. To assess the effect of both remineralization solutions on both erosive lesion types, the specimens were analyzed using surface microhardness (SMH) and field emission scanning electron microscopy (FESEM). 
Table 1. $\mathrm{Ca} / \mathbf{P}_{\mathrm{i}}$ Ratios and Composition of Simulated saliva (SS) Remineralization Solutions Used in this Study [15]

\begin{tabular}{|l|c|c|}
\hline & SS 1 & SS 2 \\
\hline \hline $\mathrm{Ca} / \mathrm{P}_{\mathrm{i}}$ ratio & 1.6 & 0.3 \\
\hline $\mathrm{Ca}^{2+}, \mathrm{mM}$ & 3.2 & 1.45 \\
\hline $\mathrm{PO}_{4}{ }^{3-}, \mathrm{mM}$ & 2.0 & 5.4 \\
\hline $\mathrm{K}^{+}, \mathrm{mM}$ & 16.9 & 20.3 \\
\hline $\mathrm{Na}^{+}, \mathrm{mM}$ & 6.5 & 6.5 \\
\hline $\mathrm{Cl}^{-}, \mathrm{mM}$ & 27.8 & 24.3 \\
\hline Tris, $\mathrm{mM}$ & 100 & 100 \\
\hline
\end{tabular}

\section{MATERIALS \& METHODS}

\section{Preparation of Enamel Specimens}

Tooth cores $3 \mathrm{~mm}$ in diameter were drilled using a hollow-core diamond drill bit (Diamond Drill Bit \& Tool, Omaha, NE, USA) by cutting perpendicularly into the labial surfaces of bovine molars and incisors. Recently, we explored the effect of different fluoride concentrations on bovine and human enamel [22]. Although the mineral content and constituent connectivity is quite similar within human and bovine enamel [23], structurally, scanning electron microscopy (SEM) has revealed sound bovine enamel manifests crystallites with diameters about 1.5 times larger than that in sound human enamel [24]. Additionally, we note that SEM [25] and infra-red [26] analyses have revealed significantly more inter-prismatic organic material exists in bovine enamel compared to human enamel. Recognizing these important characteristics, for the purposes of this study we selected bovine teeth primarily because it is readily available and procedurally easier to generate specimens.

The cores were mounted into the ends of hollowed out acrylic rods (McMaster-Carr, Chicago, IL, USA) using DuraLay mounting resin (Reliance Dental Mfg. Co., Worth, IL, USA). Each specimen was ground by hand with 600 grit $\mathrm{SiC}$ sandpaper (LECO Corporation, St. Joseph, MI, USA) under water cooling using a Spectrum System 1000 Grinder/Polisher (LECO Corporation) set to $300 \mathrm{rpm}$. Then, each specimen was polished by hand for 1 minute using 3 $\mu \mathrm{m}$ diamond compound in conjunction with microid extender solution (LECO Corporation). After rinsing with distilled (DI) water, Vickers surface microhardness was performed with a $200 \mathrm{gf}$ load and 15 second dwell time (LECO M247AT microhardness tester) to measure the surface microhardness (SMH) of sound enamel. Acceptable specimens having a Vickers Hardness Number (VHN) above 300 were then immersed in vials containing one of two concentrations of citric acid (Sigma-Aldrich, St. Louis, MO, USA): 20 specimens were immersed in $0.3 \%$ citric acid $(\mathrm{pH}=3.8)$ for 120 minutes, while another 20 were immersed in $1.0 \%$ citric acid ( $\mathrm{pH}=3.8$ ) for 30 minutes. After this initial erosion period, specimens were then analyzed again for surface microhardness (200 gf load for 15 seconds) and arranged into groups of 10 .

\section{Simulated Saliva Solutions}

The simulated saliva (SS) solutions were prepared according to the composition listed in Table 1 [15], with all chemi-
Table 2. Group Descriptions and IDs of Eroded Enamel Specimens Evaluated in this Study

\begin{tabular}{|l|c|}
\hline \multicolumn{1}{|c|}{ Group Description } & Group ID \\
\hline \hline $\begin{array}{l}\text { Initially eroded enamel (30 minutes, } 1 \% \text { citric acid) } \\
\text { treated with SS 1 }\end{array}$ & SS $1-30$ \\
\hline $\begin{array}{l}\text { Initially eroded enamel (120 minutes, } 0.3 \% \text { citric acid) } \\
\text { treated with SS 1 }\end{array}$ & SS $1-120$ \\
\hline $\begin{array}{l}\text { Initially eroded enamel (30 minutes, 1\% citric acid) } \\
\text { treated with SS 2 }\end{array}$ & SS $2-30$ \\
\hline $\begin{array}{l}\text { Initially eroded enamel (120 minutes, } 0.3 \% \text { citric acid) } \\
\text { treated with SS 2 }\end{array}$ & $\mathrm{SS} 2-120$ \\
\hline
\end{tabular}

Table 3. Outline of Daily Events Employed in the Three-Day pH Cycling Dental Model. Simulated Saliva was Refreshed for Each event. Fresh Acid (Either 0.3\% or 1\% Citric Acid, pH 3.8) was Used for each Challenge

\begin{tabular}{|l|c|}
\hline \multicolumn{1}{|c|}{ Event } & Duration \\
\hline \hline Simulated Saliva \#1, $\mathrm{pH}=7.0$ & 2 hours \\
\hline Acid Challenge \#1 & 10 minutes \\
\hline Simulated Saliva \#2, $\mathrm{pH}=7.0$ & 2 hours \\
\hline Acid Challenge \#2 & 10 minutes \\
\hline Simulated Saliva \#3, $\mathrm{pH}=7.0$ & 2 hours \\
\hline Acid Challenge \#3 & 10 minutes \\
\hline Simulated Saliva \#4, $\mathrm{pH}=7.0$ & Overnight \\
\hline
\end{tabular}

cals obtained from Fisher Scientific (Pittsburgh, PA, USA). In 2 liters of DI water, first calcium nitrate was added. After complete dissolution, potassium phosphate monobasic was added. After complete dissolution, potassium chloride was added, followed by addition of Tris buffer, which was slowly added and allowed to mix for at least 15 minutes. Slow addition of concentrated $\mathrm{HCl}$ was added to adjust the $\mathrm{pH}$ to 7.0.

\section{Treatment Groups}

There are four groups of eroded enamel specimens with two sets initially eroded by 30 -minute immersions in $1.0 \%$ citric acid and the remaining two sets initially eroded by 120 -minute immersions in $0.3 \%$ citric acid. Treatment group and identifications are summarized in Table 2.

\section{Study Phases A and B}

The study phases and microhardness measurements were performed at Indiana Nanotech (Indianapolis, IN, USA). The four groups of specimens were first immersed in one of two simulated saliva solutions for seven days according to the outline in Table 2. After the Phase A period, all ten specimens were analyzed for surface microhardness (Vickers indenter, 200 gf load, 15 second dwell time). Two random specimens from each group were subsequently pulled and sent for blinded, independent scanning electron microscopy analysis by McCrone Associates, Inc (Westmont, IL, USA). Images of carbon-coated samples were then collected using a JEOL JSM-7500F cold cathode field emission scanning electron microscope (FESEM). The secondary electron images were collected at $10 \mathrm{kV}$ at various magnifications.

The remaining eight specimens from each group were then evaluated in a pH cycling model as outlined in Table 3. Each day, specimens alternated between room-temperature 

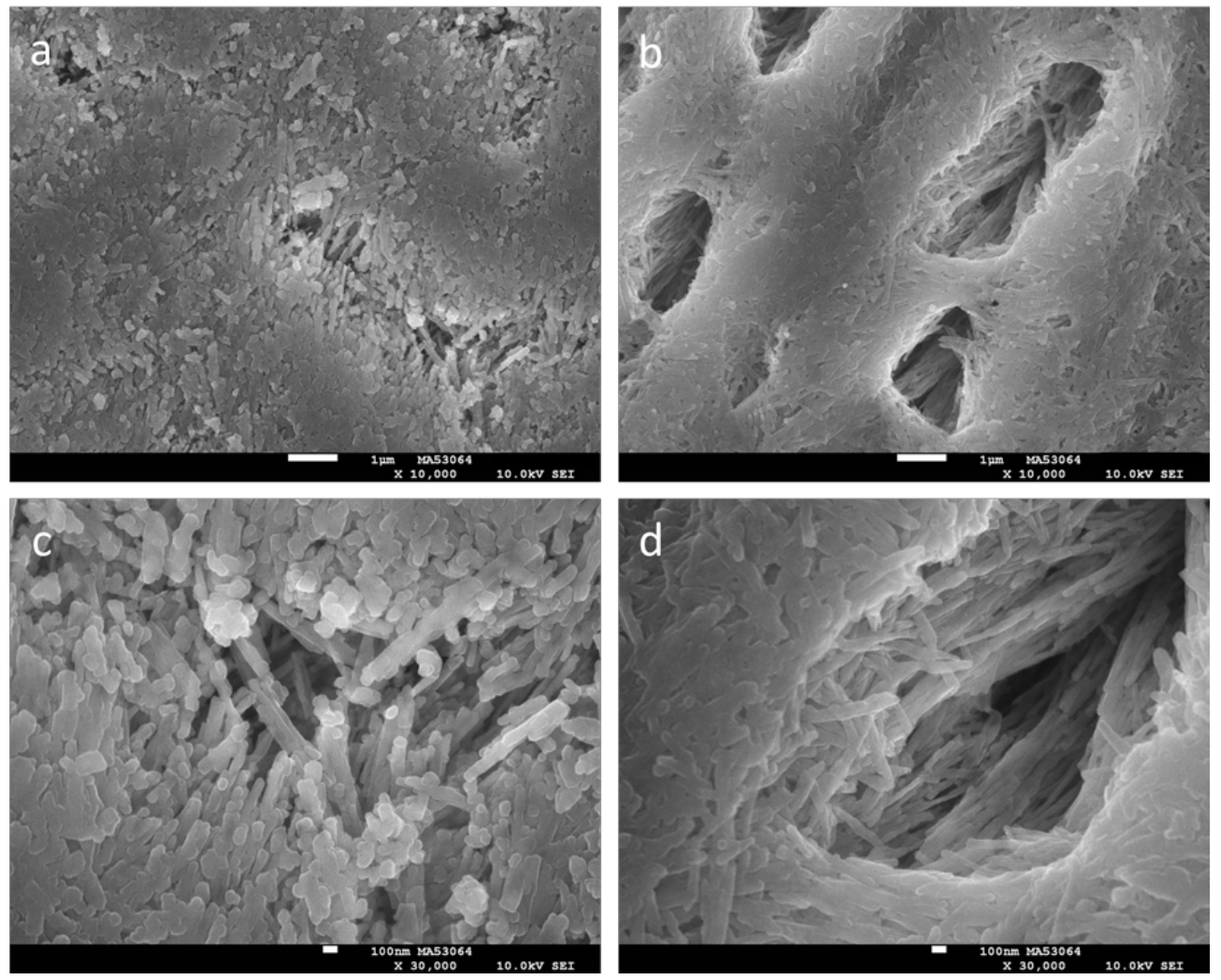

Fig. (1). SEM images at 10,000x (a, b) and 30,000x (c, d) of enamel initially eroded for 30 minutes with $1 \%$ citric acid (a, c) or 120 minutes with $0.3 \%$ citric acid $(\mathbf{b}, \mathbf{d})$. The white scale bars correspond to $1 \mu \mathrm{m}(\mathbf{a}, \mathbf{b})$ and $100 \mathrm{~nm}(\mathbf{c}, \mathbf{d})$.

Table 4. Mean (Standard Error of the Mean) Sound, Initially Softened and Seven-Day Phase A Post Surface Microhardness (SMH $\mathrm{SMH}^{\mathrm{i}}$ and $\mathrm{SMH}^{\mathrm{p}}$, Respectively) Results Obtained by Vickers Microhardness Indents (N=10). Within each Column, OneWay ANOVA was Performed and Followed by Tukey b-test Comparisons to Identify Statistical Differences $(p<0.05)$, which are Indicated as $1<2 . \% \mathrm{SMHR}^{\mathrm{p}}$ is Calculated using $\left(\mathrm{SMH}^{\mathrm{p}}-\mathrm{SMH}^{\mathrm{i}}\right) /\left(\mathrm{SMH}^{\mathrm{s}}-\mathrm{SMH}^{\mathrm{i}}\right) \times 100$

\begin{tabular}{|c|c|c|c|c|}
\hline Groups & SMH $^{\mathbf{s}}$ & SMH $^{\mathbf{i}}$ & SMH $^{\mathbf{p}}$ & \% $\mathbf{S M H R}^{\mathbf{p}}$ \\
\hline \hline SS $1-30$ & $327.6(3.9)$ & $196.9(8.8)^{2}$ & $179.5(25.3)^{1}$ & $-13.9(14.7)^{1}$ \\
\hline SS $1-120$ & $327.8(5.8)$ & $146.6(5.4)^{1}$ & $165.2(19.2)^{1}$ & $10.3(10.5)^{1}$ \\
\hline SS $2-30$ & $326.4(3.7)$ & $176.8(4.7)^{2}$ & $252.3(3.9)^{2}$ & $50.6(2.2)^{2}$ \\
\hline SS $2-120$ & $323.0(2.1)$ & $145.7(5.5)^{1}$ & $234.0(5.6)^{2}$ & $50.0(2.7)^{2}$ \\
\hline
\end{tabular}

exposures to a specific simulated saliva solution (either SS 1 or SS 2) and a specific acid challenge (either $0.3 \%$ or $1.0 \%$ citric acid). The soak in simulated saliva was dynamic $(300$ rpm) while the acid challenge was static, with fresh simulated saliva and citric acid solutions used for each event. In between these exposures, the specimens were briefly and thoroughly rinsed with DI water. All specimens were inverted during simulated saliva and acid challenge periods. After this three-day Phase B period, the specimens were again analyzed for surface microhardness and scanning electron microscopy as described above.

\section{Statistical Analysis}

Statistical analyses were conducted using IBM SPSS statistical software (version 19), with the level of significance selected at 0.05 . The mean (standard error of the mean) surface microhardness (SMH) values were calculated for each group and were compared using ANOVA followed by Tukey b-test comparisons at the $95 \%$ confidence level.

\section{RESULTS}

Representative SEM images of initially eroded enamel are shown in Fig. (1) at 10,000x and 30,000x magnification. Although both citric acid solutions produced significant surface demineralization, initial erosion by the $1 \%$ citric acid solution produced morphologies that contrast markedly with the erosion by $0.3 \%$ citric acid. In particular, the $0.3 \%$ citric acid erosion created wider and deeper demineralization compared to the $1.0 \%$ citric acid erosion. The erosion resulting from the initial $0.3 \%$ citric acid soak leads to ellipticalshaped pore openings several microns in length and appears to extend several microns below the enamel surface. In contrast, the $1 \%$ citric acid soak does not produce the similar porosity, although penetration appears to be significant and also extends below the enamel surface. SMH values for initially eroded enamel $\left(\mathrm{SMH}^{\mathrm{i}}\right)$ are summarized in the third column of Tables 4 (for ten specimens) and 5 (for eight specimens). In both tables, the $0.3 \%$ citric acid soak pro- 

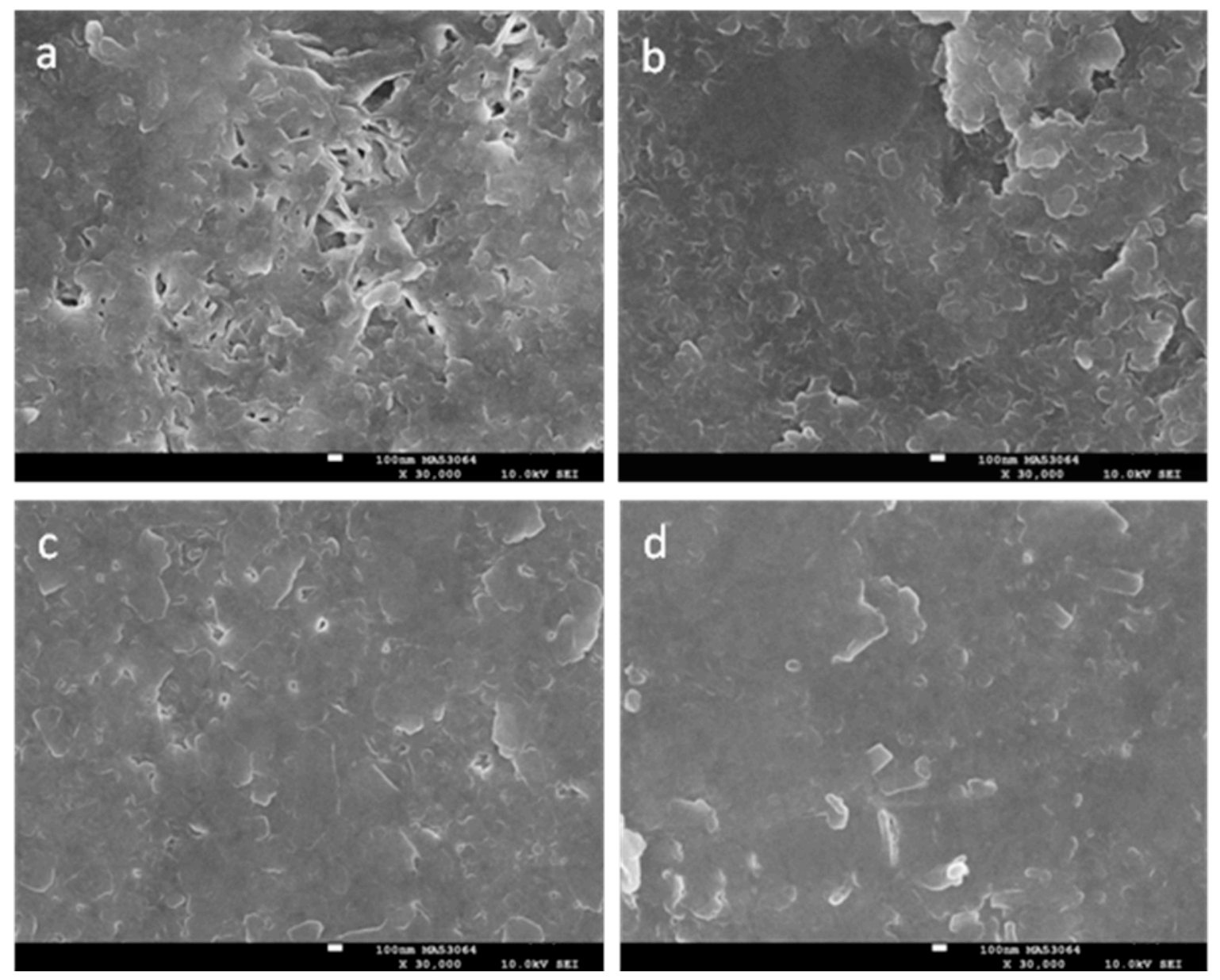

Fig. (2). SEM images after the seven-day remineralization Phase A period at 30,000x for enamel initially eroded for 30 minutes with $1 \%$ citric acid $(\mathbf{a}, \mathbf{c})$ or 120 minutes with $0.3 \%$ citric acid $(\mathbf{b}, \mathbf{d})$ and treated with either SS $1(\mathbf{a}, \mathbf{b})$ or SS $2(\mathbf{c}, \mathbf{d})$. The white scale bars correspond to $100 \mathrm{~nm}$.

Table 5. Mean (standard error of the mean) sound, initially softened and three-day Phase B post surface microhardness (SMH', $\mathrm{SMH}^{\mathrm{i}}$ and $\mathrm{SMH}^{\mathrm{p}}$, respectively) results obtained by Vickers microhardness indents $(\mathrm{N}=8)$. Within each column, one-way ANOVA was performed and followed by Tukey b-test comparisons to identify statistical differences $(p<0.05)$, which are indicated as $1<2<3 . \% \mathrm{SMHR}^{\mathrm{p}}$ is calculated using $\left(\mathrm{SMH}^{\mathrm{p}}-\mathrm{SMH}^{\mathrm{i}}\right) /\left(\mathrm{SMH}^{\mathrm{s}}-\mathrm{SMH}^{\mathrm{i}}\right) \times 100$

\begin{tabular}{|c|c|c|c|c|}
\hline Groups & SMH $^{\mathbf{s}}$ & $\mathbf{S M H}^{\mathbf{i}}$ & $\mathbf{S M H}^{\mathbf{p}}$ & \% $\mathbf{S M H R}^{\mathbf{p}}$ \\
\hline \hline SS 1-30 & $326.3(4.4)$ & $189.6(9.2)^{2}$ & $168.3(29.0)^{1}$ & $-15.6(16.1)^{1}$ \\
\hline SS $1-120$ & $326.2(6.5)$ & $151.7(5.4)^{1}$ & $192.5(27.1)^{1}$ & $23.6(15.1)^{2}$ \\
\hline SS $2-30$ & $326.1(3.6)$ & $177.1(5.6)^{2}$ & $216.4(6.3)^{1,2}$ & $25.9(3.2)^{2}$ \\
\hline SS 2 - 120 & $322.9(2.7)$ & $148.8(5.8)^{1}$ & $271.3(3.1)^{2}$ & $70.4(2.2)^{3}$ \\
\hline
\end{tabular}

duced statistically weaker enamel relative to enamel SMH after the $1.0 \%$ citric acid soak.

SMH and representative SEM results after the seven-day Phase A period using either SS 1 or SS 2 are shown in Table 4 and Fig. (2), respectively. The SMH increased for each treatment group except SS $1-30$, which decreased. Both SS 2 treatments were not significantly different from one another but produced significantly greater SMH relative to both SS 1 treatments, which did not differ significantly. SEM reveals morphological similarities for both SS 2 treatments, with the formation of non-porous mineralized layers. This contrasts to the morphology observed from the SS $1-30$ treatment, where a porous mineralization is observed. Rela- tively improved mineralization was observed for the SS 1 120 treatment but was not as uniform compared to the each of the SS 2 treatments.

SMH and representative SEM results after the three-day Phase $\mathrm{B} \mathrm{pH}$ cycling period using either SS 1 or SS 2 are shown in Table 5 and Fig. (3), respectively. SMH data in Table 5 show that the SS $1-30$ treatment produced the softest mineral relative to the other three treatments. Fig. (3a) supports this assessment through the observation of a porous then tread morphology that differs markedly from the other three images in Fig. (3) and appears reminiscent of octacalcium phosphate or hydroxyapatite crystals [22]. SMH appeared similar for both SS $1-120$ and SS $2-30$, and the 

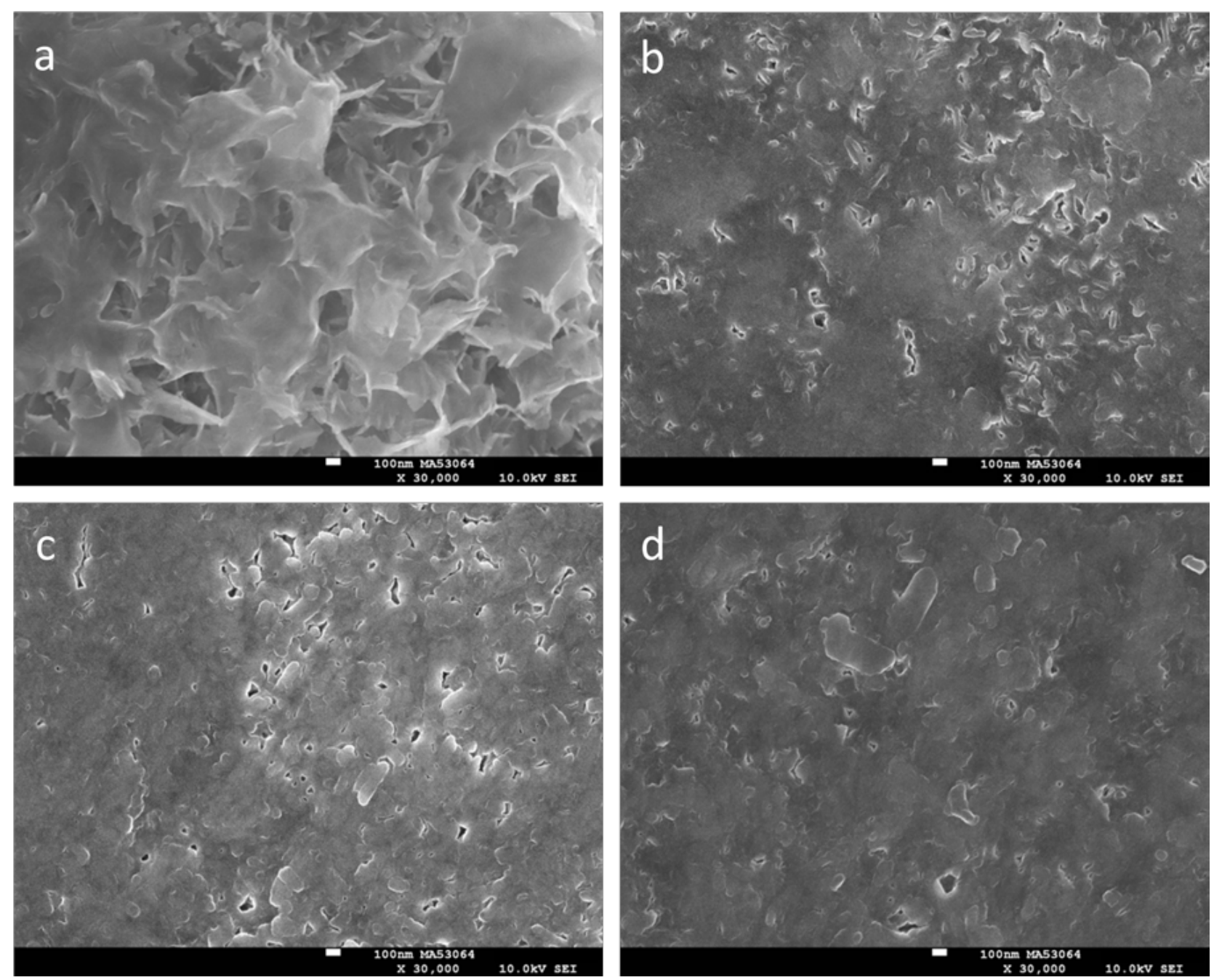

Fig. (3). SEM images after the Phase B three-day pH cycling model at 30,000x for enamel initially eroded for 30 minutes with $1 \%$ citric acid (a, c) or 120 minutes with $0.3 \%$ citric acid $(\mathbf{b}, \mathbf{d})$ and treated with either SS $1(\mathbf{a}, \mathbf{b})$ or SS $2(\mathbf{c}, \mathbf{d})$. The white scale bars correspond to $100 \mathrm{~nm}$.

relatively low porosity as shown in Fig. (3b and 3c) appeared comparable as well. Relative to the SMH obtained after the Phase A period, after the three-day cycling period the SS 2-30 treatment produced lower SMH. Concomitant with this $\mathrm{SMH}$ reduction was an observed relative increase in surface porosity as shown in the SEM images of Figs. (2c and 3c). The greatest SMH occurred for the SS $2-120$ treatment, which was significantly higher relative to the remaining three treatment groups, and also produced the greatest mineralization based on visual observations (Fig. 3d).

\section{DISCUSSION}

Proper in vitro modeling is required to better mirror clinical observations [3, 4]. Although proteins and other salivary organic constituents contribute significant anti-erosion properties [19], calcium and phosphate also serve an important role as well [17]. One way to improve in vitro modeling might be to focus on simulated saliva solutions, and could also influence design strategies of anti-erosion therapies for populations using saliva substitutes. Just as eroded dentin responds differently to different $\mathrm{Ca} / \mathrm{P}_{\mathrm{i}}$ ratios $[15,16]$, eroded enamel may also respond uniquely to simulated saliva solutions having different $\mathrm{Ca} / \mathrm{P}_{\mathrm{i}}$ ratios, which in turn may bear on clinical observations.
The aim of the present study was to determine whether initially eroded enamel would be remineralized differently using either a calcium-rich or a phosphate-rich simulated saliva solution. In this study, significant differences were observed in morphology and surface microhardness, which supports the rejection of the null hypothesis. For our evaluations we used SMH and SEM, since these techniques have been used to assess dental erosion [9-11, 19, 28, 29]. For initial erosion, we used either $0.3 \%$ or $1.0 \%$ citric acid, since these concentrations are within the range typically found in commercially available acidic beverages [30, 31], and used relatively long soak periods to ensure substantial demineralization had commenced and is consistent with clinical observations of patients exhibiting dental erosion [32]. To this end, specimens initially eroded with $0.3 \%$ citric acid for 120 minutes produced approximately one-half the SMH compared to sound enamel, while the $1.0 \%$ citric acid for 30 minutes resulted in SMH reductions of approximately onethird. These SMH reductions may be related to morphology as shown in the corresponding SEM images.

Based on differences in initial erosive conditions and our non-use of replicas and/or freeze-dried techniques, the morphology of the initially eroded enamel specimens contrast with those reported for other eroded specimens [19, 28, 33]. 
Importantly, the initial conditions chosen in this study compare to those used in previous in situ studies $[6,13]$. In one study, the remineralization effects of $\mathrm{NaF}$ rinses on enamel specimens initially eroded for 120 minutes using $0.3 \%$ citric acid $(\mathrm{pH}=3.75)$ were evaluated [13]. That study revealed an overall net remineralization for all groups (including the fluoride-free control). Though strong comparisons between the in situ and the present in vitro studies cannot be made due to different protocols and treatment groups, both simulated saliva solutions used herein produced net remineralization, with the $0.3 \mathrm{Ca} / \mathrm{P}_{\mathrm{i}}$ ratio simulated saliva providing the greatest benefits. The overall net remineralization observations appear to demonstrate some consistency between these in vitro results and the outcome from the in situ study.

Separately, another in situ study incorporated initial lesions formed using $1.0 \%$ citric acid (30 minute soak), although the $\mathrm{pH}$ differed from the present study (i.e. 2.5 vs 3.8) [6]. Similar to the other study, overall net remineralization was observed (including the fluoride-free control), and those results suggest (albeit loosely, due to protocol and treatment differences) the $0.3 \mathrm{Ca} / \mathrm{P}_{\mathrm{i}}$ ratio simulated saliva solution might provide a better clinical correlation since the 1.6 Ca/ $\mathrm{P}_{\mathrm{i}}$ ratio simulated saliva produced overall negative remineralization. One reason the $1.6 \mathrm{Ca} / \mathrm{P}_{\mathrm{i}}$ ratio simulated saliva might have failed to produce surface strengthening of eroded lesions initially eroded with $1.0 \%$ citric acid could be due to the design of the solution, which encourages hydroxyapatite formation (including precipitation) [20, 27, 34]. In this case, since the lesion was not as porous compared to the $0.3 \%$ citric acid lesion (e.g. SEM images in Fig. 1) mineral depositions were not able to penetrate throughout the erosive lesion and were therefore limited to the surface. Likewise, the relatively high porosity of the $0.3 \%$ citric acid erosive lesion appeared to accommodate remineralization and/or mineral depositions from the $1.6 \mathrm{Ca} / \mathrm{P}_{\mathrm{i}}$ ratio simulated saliva. These visual observations may also contribute to the contrasting SMH results from exposure of the $0.3 \%$ and $1.0 \%$ citric acid erosive lesions to the $1.6 \mathrm{Ca} / \mathrm{P}_{\mathrm{i}}$ ratio simulated saliva solution. Nevertheless, these assessments reveal that it is important to select simulated saliva solutions for in vitro studies that can provide the best agreement with clinical evaluations. Studies on eroded dentin using transverse microradiography have shown that in addition to supersaturation with respect to certain calcium phosphate phases (e.g. octacalcium phosphate or dicalcium phosphate dihydrate), phosphate-rich simulated saliva solutions can provide better remineralization benefits compared to calcium-rich solutions $[15,16]$. While the surface microhardness and SEM results on eroded enamel reported in this study expands on the research previously conducted on eroded dentin, this study demonstrates the remineralization effects from two distinct $\mathrm{Ca} / \mathrm{P}_{\mathrm{i}}$ ratios, with the phosphate-rich solution apparently providing relatively greater benefits. One explanation for this may be due to the isomorphoric exchange of phosphate for carbonate in the enamel lattice [35], which readily dissolves during acid attack. Since calcium can coordinate with many neighboring species depending on its environments (e.g. the coordination can exceed 10, for instance) [36-38], it could be that relatively higher levels of phosphate may be needed to help stabilize surviving calcium constituents remaining in the eroded enamel framework.
We acknowledge inherent difficulties in predicting success a priori, so an iterative approach among laboratory and clinical studies may be needed, even though this may be resource intensive. Although we have only emphasized inorganic agents in this study, we also recognize the organic components of saliva play an important role. However, the mineralizing capabilities of organic constituents are limited relative to inorganic species and the purpose of this study was to explore remineralization characteristics arising from simulated saliva solutions having contrasting $\mathrm{Ca} / \mathrm{P}_{\mathrm{i}}$ ratios. Observations supporting calcium supplementation in beverages are sound $[9,31,32]$, and these in vitro results might suggest, in combination with follow-on studies utilizing various acidic beverages, there are opportunities in supplementing beverages with a given $\mathrm{Ca} / \mathrm{P}_{i}$ ratio. We imagine this supplementation might be dependent on the type, concentration and $\mathrm{pH}$ of the acid found in the beverage. Such ratios may also play a role in the design of simulated saliva antierosion therapies for hyposalivary populations.

\section{CONFLICT OF INTEREST/DISCLOSURE STATE- MENT}

The content is solely the responsibility of the authors and does not necessarily represent the official views of the NIDCR or the National Institutes of Health. The authors declare no potential conflicts of interest related to this work.

\section{ACKNOWLEDGEMENTS}

We kindly acknowledge technical support from Lauren Dodge and Katherine Frederick for enamel specimen preparation. This research was partially supported by grant number R44DE018576 from the National Institutes of Dental \& Craniofacial Research (NIDCR).

\section{REFERENCES}

[1] Huysmans MCDNJM, Chew HP, Ellwood RP. Clinical studies of dental erosion and erosive wear. Caries Res 2011; 45: 60-8.

[2] Zero DT, Lussi AA. Erosion - chemical and biological factors of importance to the dental practitioner. Int Dent J 2005; 55: 285-90.

[3] West NX, Davies M, Amaechi BT. In vitro and in situ erosion models for evaluating tooth substance loss. Caries Res 2011; 45 : 43-52.

[4] Young A, Tenuta LMA. Initial erosion models. Caries Res 2011; 45: 33-42.

[5] Karlinsey RL, Mackey AC, Walker ER, Frederick KE, Fowler C. In vitro evaluation of eroded enamel treated with fluoride and a prospective tricalcium phosphate agent. J Dent Oral Hyg 2009; 1: 52-8.

[6] Amaechi BT, Karthikeyan R, Mensinkai PK, Najibfard K, Mackey AC, Karlinsey RL. Remineralization of eroded enamel by a $\mathrm{NaF}$ rinse containing a novel calcium phosphate agent in an in situ model: a pilot study. Clin Cosmet Invest Dent 2010; 2: 93-100.

[7] Jensdottir T, Nauntofte B, Buchwald C, Bardow A. Effect of calcium on the erosive potential of acidic candies in saliva. Caries Res 2007; 41: 68-73.

[8] Lagerweij MD, Buchalla W, Kohnke W, Becker K, Lennon AM, Attin T. Prevention of erosion and abrasion by a high fluoride concentration gel applied at high frequencies. Caries Res 2006; 40 : 148-53.

[9] Hara AT, Zero DT. Analysis of the erosive potential of calciumcontaining acidic beverages. Eur J Oral Sci 2008; 116: 60-5.

[10] Lussi A, Jaggi T, Scharer S. The influence of different factors on in vitro enamel erosion. Caries Res 1993; 27: 387-93.

[11] Collys K, Cleymaet R, Coomans D, Michotte Y, Slop D. Rehardening of surface softened and surface etched enamel in vitro and by intraoral exposure. Caries Res 1993; 27: 15-20. 
[12] Yu H, Wegehaupt FJ, Zaruba M, et al. Erosion-inhibiting potential of a stannous chloride-containing fluoride solution under acid flow conditions in vitro. Arch Oral Biol 2010; 55: 702-5.

[13] Mathews MS, Amaechi BT, Ramalingam K, et al. In situ remineralisation of eroded enamel lesions by $\mathrm{NaF}$ rinses. Arch Oral Biol 2012; 57: 525-30.

[14] Ganss C, Neutard L, von Hinckeldey J, Klimek J, Schlueter N. Efficacy of a tin/fluoride rinse: a randomized in situ trial on erosion. J Dent Res 2010; 89: 1214-8.

[15] Hara AT, Karlinsey RL, Zero DT. Dentine remineralisation by simulated saliva formulations with different $\mathrm{Ca}$ and $\mathrm{P}_{\mathrm{i}}$ contents. Caries Res 2008; 42: 51-6.

[16] Tschoppe P, Kielbassa AM, Meyer-Lueckel H. Evaluation of the remineralising capacities of modified saliva substitutes in vitro. Arch Oral Biol 2009; 54: 810-6.

[17] Amaechi BT, Higham SM. In vitro remineralization of eroded enamel lesions by saliva. J Dent 2001; 29: 371-6.

[18] Wetton S, Hughes J, West N, Addy M. Exposure time of enamel and dentine to saliva for protection against erosion: a study in vitro. Caries Res 2006; 40: 213-7.

[19] Hannig M, Fiebiger M, Guntzer M, Dobert A, Zimehl R, Nekrashevych Y. Protective effect of the in situ formed short-term salivary pellicle. Arch Oral Biol 2004; 49: 903-10.

[20] Koulorides T, Cueto H, Pigman W. Rehardening of softened enamel surfaces of human teeth by solutions of calcium phosphates. Nature 1961; 189: 226-7.

[21] Jenkins G. The physiology and biochemistry of the mouth, $4^{\text {th }}$ ed. Oxford England: Blackwell 1978.

[22] Karlinsey RL, Mackey AC, Walker $\mathrm{TJ}$, et al. In vitro remineralization of human and bovine white-spot enamel lesion by NaF dentifrices: a pilot study. J Dent Oral Hyg 2011; 3: 22-9.

[23] Bachmann L, Diebolder R, Hibst R, Zezell DM. Infrared absorption bands of enamel and dentin tissues from human and bovine teeth. Appl Spectrosc Rev 2003; 38:1-14.

[24] Arends J, Jongebloed WL. Crystallite dimensions of enamel. J Biol Buccale 1978; 6: 161-71.

[25] Fonseca RB, Haiter-Neto F, Carlo HL, et al. Radiodensity and hardness of enamel and dentin of human and bovine teeth, varying bovine teeth age. Arch Oral Biol 2008; 53:1023-9.
[26] Spitzer D, ten Bosch JJ. The absorption and scattering of light in bovine and human dental enamel. Calcif Tissue Res 1975;17: 12937.

[27] Nancollas GH, Wefel JS. Seeded growth of calcium phosphates: effect of different calcium phosphate seed material. J Dent Res 1976; 55: 617-24.

[28] Eisenburger M, Shellis RP, Addy M. Scanning electron microscopy of softened enamel. Caries Res 2004; 38: 67-74.

[29] Gedalia I, Ionat-Bendat D, Ben-Mosheh S, Shapira L. Tooth enamel softening with a cola type drink and rehardnening with the hard cheese or stimulated saliva in situ. J Oral Rehabil 1991;18: 501-6.

[30] West NX, Hughes JA, Addy M. Erosion of dentine and enamel in vitro by dietary acids: the effect of temperature, acid character, concentration and exposure time. J Oral Rehabil 2000; 27: 875-80.

[31] Hughes JA, West NX, Parker DM, van den Braak MH, Addy M. Effects of $\mathrm{pH}$ and concentration of citric, malic and lactic acids on enamel, in vitro. J Dent 2000; 28:147-52.

[32] Lussi A, Jaeggi T, Zero D. The role of diet in the aetiology of dental erosion. Caries Res 2004; 38: 34-44.

[33] Meurman JH, Frank RM. Progression and surface ultrastructure of in vitro caused erosive lesions in human and bovine enamel. Caries Res 1991; 25: 81-7.

[34] Nancollas GH, Tomazic B. Growth of calcium phosphate on hydroxyapatite crystals. Effect of supersaturation and ionic medium. J Phys Chem 1974; 78: 2218-25.

[35] Aoba T, Moreno EC. Changes in the nature and composition of enamel mineral during porcine amelogenesis. Calcif Tissue Res 1990; 47: 356-64.

[36] Pauling L. The Nature of the Chemical Bond, $3^{\text {rd }}$ ed. Cornell University Press, NY: Ithaca 1960.

[37] Chiari G. On metal-oxygen coordination: a statistical method to determine coordination number. I. Calcium. Acta Crystallogr 1990; B46: 717-23.

[38] Katz AM, Glusker JP, Beebe SA, Bock CW. Calcium ion coordination: a comparison with that of beryllium, magnesium, and zinc," J Am Chem Soc 1996; 118: 5752-63.

(C) Karlinsey et al.; Licensee Bentham Open .

This is an open access article licensed under the terms of the Creative Commons Attribution Non-Commercial License (http://creativecommons.org/licenses/by-nc/3.0/) which permits unrestricted, non-commercial use, distribution and reproduction in any medium, provided the work is properly cited. 